\title{
Gestión de recursos humanos en organismos de agua de Hermosillo y Mexicali
}

\section{Human resources management in the water utilities of Hermosillo and Mexicali}

Recibido el 6 de abril de 2016.

Aceptado el 1 de noviembre de 2016

*Autor para correspondencia: Alejandro Salazar Adams, correo electrónico: asalazar@colson.edu.mx
Todos los contenidos de Estudios Fronterizos se publican bajo la licencia Creative Commons Atribución no comercial 2.5 México, y pueden ser usados gratuitamente para fines no comerciales, dando el crédito a los autores y a la revista Estudios Fronterizos.

\section{Resumen}

Este estudio investiga cómo los Sistemas de Gestión de Recursos Humanos (SGRH) impactan en el desempeño de los Organismos Operadores de Agua Potable (OOAP) en México. Se comparó el desempeño diferenciado de los OOAP de Hermosillo y Mexicali con las características de sus SGRH a través del análisis de cuatro categorías: 1) Políticas de contratación de personal, 2) Desarrollo y capacitación, 3) Salario, prestaciones y estímulos, y 4) Sanciones. Las principales diferencias se encuentran en las categorías 2 y 3, en donde Mexicali cuenta con niveles más altos. El estudio aporta una visión desde los SGRH, variable que no se ha analizado a profundidad en el estudio de los OoAP. A pesar de que Mexicali capacita e incentiva mejor a sus empleados, se observa que la influencia del poder ejecutivo y la excesiva injerencia de los sindicatos han contribuido en la configuración de un endeble SGRH que afecta al desempeño de ambos OOAP.

Palabras clave: sistema de gestión de recursos humanos, organismos de agua, eficiencia, patrimonialismo, desempeño.

\section{Abstract}

This paper studies how the Human Resources Management Systems (HRMs) influence the performance of water utilities in Mexico. The differentiated performance of the water utilities of the cities of Hermosillo and Mexicali were compared to their HRMs characteristics through the analysis of four categories: 1) Hiring policies, 2) Development and training, 3) Salaries, benefits and incentives, and 4) Sanctions systems. The main differences between these utilities are

CÓMO CITAR: Loera, E. y Salazar, A. (2017). Gestión de recursos humanos en organismos de agua de Hermosillo y Mexicali [Human resources management in the water utilities of Hermosillo and Mexicali]. Estudios Fronterizos, 18(36), 25-53, doi:10.21670/ref.2017.36.a02 
on categories 2 and 3, where Mexicali shows greater levels. The study provides a vision of water utilities from the point of view of HRMG, which has not been taken into account in previous research. Although Mexicali provides its workers with better training and incentives, it is observed that the influence of local governments and the excessive power of unions have led to weak HRMs that affect the performance of water utilities.

Keywords: human resourses management system, water utilities, efficiency, patrimonialism, performance.

\section{Introducción}

Los organismos operadores de agua (OOA) de México presentan serios rezagos en su desempeño que comprometen su sustentabilidad, tanto ambiental como financiera (Salazar y Lutz, 2015), lo que pone en riesgo la provisión de agua potable en las ciudades, sobre todo las que cuentan con menor disponibilidad natural de agua, como las ubicadas en el norte del país que es una región árida pero con un dinamismo económico y poblacional que hace cada vez más importante la adecuada gestión de los recursos hídricos.

Si bien se han identificado distintos factores que inciden en el desempeño de los organismos de agua, se carecen de estudios que tomen como elemento central el análisis de la gestión de los recursos humanos. Estudios previos (véase por ejemplo a Lutz y Salazar, 2012; Pineda y Briseño, 2012) se han limitado a señalar el número de empleados por cada 1000 tomas y la discrecionalidad que impera en la designación del personal directivo, pero no han profundizado en el análisis de otros elementos que son claves para entender el desempeño del aparato burocrático, que es el que opera los sistemas de agua potable y es responsable directo de su funcionamiento.

Kneedler, Selden e Ingraham (2000) al analizar los Sistemas de Gestión de Recursos Humanos (SGRH) de 29 ciudades de los Estados Unidos de América a través de variables de sindicalización y estructura de gobierno, encontraron que las ciudades en donde persiste un gobierno tradicional con un alto nivel de sindicalización tienen un sistema de gestión poco eficiente ya que las reglas que persisten inhiben la contratación de personal calificado, además de que carecen de incentivos para estimular la permanencia y desempeño de la planta laboral con base en resultados. En estas circunstancias, los sindicatos tratan de influir en la contratación de personal y en el establecimiento de recompensas, evitando que se adhiera a la planta laboral el personal mejor calificado. Si esta situación se presenta en un país de larga tradición democrática y con un longevo servicio civil de carrera, cabría esperar que estos problemas afecten de manera más pronunciada al desempeño de la gestión pública en una democracia joven como la mexicana y con muy poco desarrollo del servicio civil, principalmente a nivel de gobiernos locales que es donde se desarrolla la gestión del agua potable.

El objetivo de este artículo es realizar un estudio exploratorio respecto a las características de los SGRH de dos organismos de agua del norte de México con desempeño diferenciado, en este caso Agua de Hermosillo y la Comisión Estatal de Servicios Públicos de Mexicali (CESPM) a través del análisis de cuatro categorías: 1) Políticas de contratación de personal, 2) Desarrollo y capacitación, 3) Salario, prestaciones y estímulos y, 4) Sanciones. El estudio parte de la hipótesis de que los SGRH se encuentran influenciados por factores como la injerencia del titular del ejecutivo 
y los sindicatos, lo que obstruye la implementación de un servicio civil de carrera de carácter meritorio, lo que a su vez afecta a la calidad del suministro de agua.

Ambos organismos tienen condiciones geográficas, demográficas y socioeconómicas similares: se localizan en el norte árido de México, en municipios donde la temperatura en el verano frecuentemente supera $\operatorname{los} 45^{\circ} \mathrm{C}$; de acuerdo al Consejo Nacional de Población (Conapo) (2015), Hermosillo y Mexicali se encuentran catalogados como municipios de muy bajo grado de marginación, además tienen la misión de suministrar agua a una población de tamaño similar en condiciones de escasez. Sin embargo, el desempeño ha sido diferenciado, ya que en Mexicali existen menores pérdidas de agua y mantiene un suministro constante, mientras que en Hermosillo se tiene un alto nivel de agua no contabilizada y ha tenido que recurrir al racionamiento en algunos años. La percepción de los usuarios refleja estas diferencias en el desempeño: según datos de la Encuesta Nacional de Calidad e Impacto Gubernamental (ENCIG) (Instituto Nacional de Geografía y Estadística [Inegi], 2015), en Mexicali 97\% de los entrevistados indican que el suministro es constante, $87 \%$ que el agua es clara y cristalina y califican al servicio de agua potable con 8.5 . En contraste, $72 \%$ opinan que en Hermosillo el suministro es constante, $67 \%$ que el agua es cristalina y la calificación promedio que le otorgan al servicio es de 6.7.

El contexto político institucional de ambos organismos presenta algunas diferencias: en el estado de Baja California desde 1989 hay alternancia política en la gubernatura y en las presidencias municipales, en cambio, en Sonora es hasta el año 2009 cuando gobierna un partido distinto al PRI aunque en la presidencia municipal de Hermosillo la alternancia es frecuente a partir de los años noventa. Además la CESPM es un organismo paraestatal mientras que Agua de Hermosillo es paramunicipal. Sin embargo, estas diferencias no son suficientes para explicar por qué el desempeño de Mexicali ha sido mejor: se requiere estudiar a fondo los factores que inciden sobre el manejo de los recursos hídricos en ambos OOA, siendo un elemento clave el personal encargado de llevar a cabo la gestión del agua en estos municipios.

El periodo de estudio de la investigación es del año 2003 al 2012, para lo cual se realizó trabajo bibliográfico, hemerográfico y entrevistas a funcionarios de la CESPM, representantes o miembros de partidos políticos locales. En el caso de Hermosillo, no fue posible entrevistar a funcionarios del organismo, pero se obtuvo información a través de entrevistas a informantes clave, entre ellos un ex miembro del Consejo Consultivo de Agua de Hermosillo y el Presidente de la Unión de Usuarios de Hermosillo. Finalmente, se realizó un análisis de los contratos colectivos de trabajo (ССT), tanto de la CESPM como de Agua de Hermosillo, así como de las cuentas públicas y solicitudes de información.

Por otra parte, un estudio comparativo proporciona la riqueza de poder contrastar dos objetos de estudio, pero también limita la profundidad en el análisis. En este sentido, el sistema de gestión de recursos humanos es un concepto muy amplio que implica el análisis minucioso de varias categorías ${ }^{1}$, sin embargo, y ante la imposibilidad de analizar cada una de ellos se seleccionaron las cuatro categorías anteriormente mencionadas, ya que son las que reflejan con mayor claridad los principales obstáculos que enfrentan las organizaciones públicas para implementar un eficiente sistema de gestión de recursos humanos.

${ }^{1}$ Por lo tanto, análisis y descripción de puestos, valuación de puestos, higiene y seguridad, entre otras, quedaron fuera del análisis. 
Si bien existen otros elementos que influyen sobre el desempeño de los ooA, el presente documento se limita unicamente a analizar los SGRH, que han sido poco estudiados en el sector, pero son parte fundamental en el funcionamiento de los sistemas de agua potable. El estudio se estructuró en cuatro apartados: en el primero, se presentan las características y el desempeño de los organismos operadores de agua (OOA) de Hermosillo y Mexicali; en el segundo, se expone un esbozo general de los SGRH en México y el mundo, así como algunos casos de éxito en el sector agua en países de Asia; en el tercero, se revisan y comparan los SGRH de los organismos operadores de agua de Hermosillo y Mexicali a través de las cuatro categorías anteriormente mencionadas. Finalmente, se presentan las conclusiones.

\section{Características y desempeño de Agua de Hermosillo y la Comisión Estatal de Servicios Públicos de Mexicali}

La reforma en materia de agua potable implementada a fínales de la década de los años ochenta, puso especial énfasis en el gasto y su impacto en el desempeño de los organismos. Con este propósito la política de la Comisión Nacional del Agua (Conagua), se resume en los siguientes objetivos:

1. Ampliar la cobertura y calidad de agua potable y alcantarillado.

2. Mejorar la eficiencia física y comercial de los organismos.

3. Incrementar los ingresos de los organismos por consumo de agua.

4. Sanear y/o tratar las aguas residuales (Conagua, s.f.).

Dos décadas después, se observan avances, sobre todo en la cobertura y alcantarillado, en donde se incrementó de $70 \%$ en 1990 a $90 \%$ en 2012; de igual forma, el tratamiento de aguas residuales de $28.1 \%$ en el año 2002 pasó a $51 \%$ en el 2012. En otras, mantienen niveles de desempeño muy similares como la eficiencia global que en el año 2002 reportaba un promedio de $43.8 \%$ y en el 2012 fue de $43.2 \%$, o la relación costo-tarifa, que de un déficit de 3.3 pesos registrado en el 2012, se incrementó ligeramente en el 2012 (3.6 pesos) (Programa de Indicadores de Gestión de Organismos Operadores [PIGoo], Instituto Mexicano de Tecnología del Agua [IMTA] y Secretaría de Medio Ambiente, Recursos Naturales [Semarnat], s.f.).

Este desempeño es insatisfactorio, considerando que para lograrlo se invirtieron grandes cantidades de recursos. En 1991 la inversión fue de 2563 millones de pesos (mdp), pero es hasta el año 2000 cuando se incrementa 65\%. A partir del 2003 las inversiones registran más de 7000 mdp anuales. En el año 2012 la cifra alcanzó los 34287.9 mdp, de los cuales 67\% fueron recursos federales (Conagua, 2013). Esta información indica que en términos generales, la autosustentabilidad física, financiera y ambiental, sigue siendo un objetivo difícil de alcanzar. Sin embargo, encontramos organismos que han logrado obtener resultados satisfactorios.

Considerando estos antecedentes, y teniendo claro que en el desempeño de los organismos de agua intervienen distintas variables, el estudio parte del hecho de que los organismos de agua de Hermosillo y Mexicali presentan resultados diferenciados, a pesar de compartir algunas características semejantes tales como la geografía, clima, precipitación pluvial y tamaño similar de población. El desempeño de estos oOA se determinó a partir del promedio de las cuatro categorías señaladas por la Conagua: cobertura del servicio (incluye agua, drenaje y alcantarillado, y continuidad del 
servicio); eficiencia (física y comercial); sustentabilidad financiera (ingresos menos egresos), y ambiental (tratamiento de aguas residuales). La Tabla 1 muestra que el desempeño de Mexicali ha sido mucho mejor que el de Hermosillo. A continuación se presentan algunos aspectos generales que explican esta diferencia.

Tabla 1: Desempeño de los organismos operadores de agua de Mexicali y Hermosillo durante el periodo 2003-2012

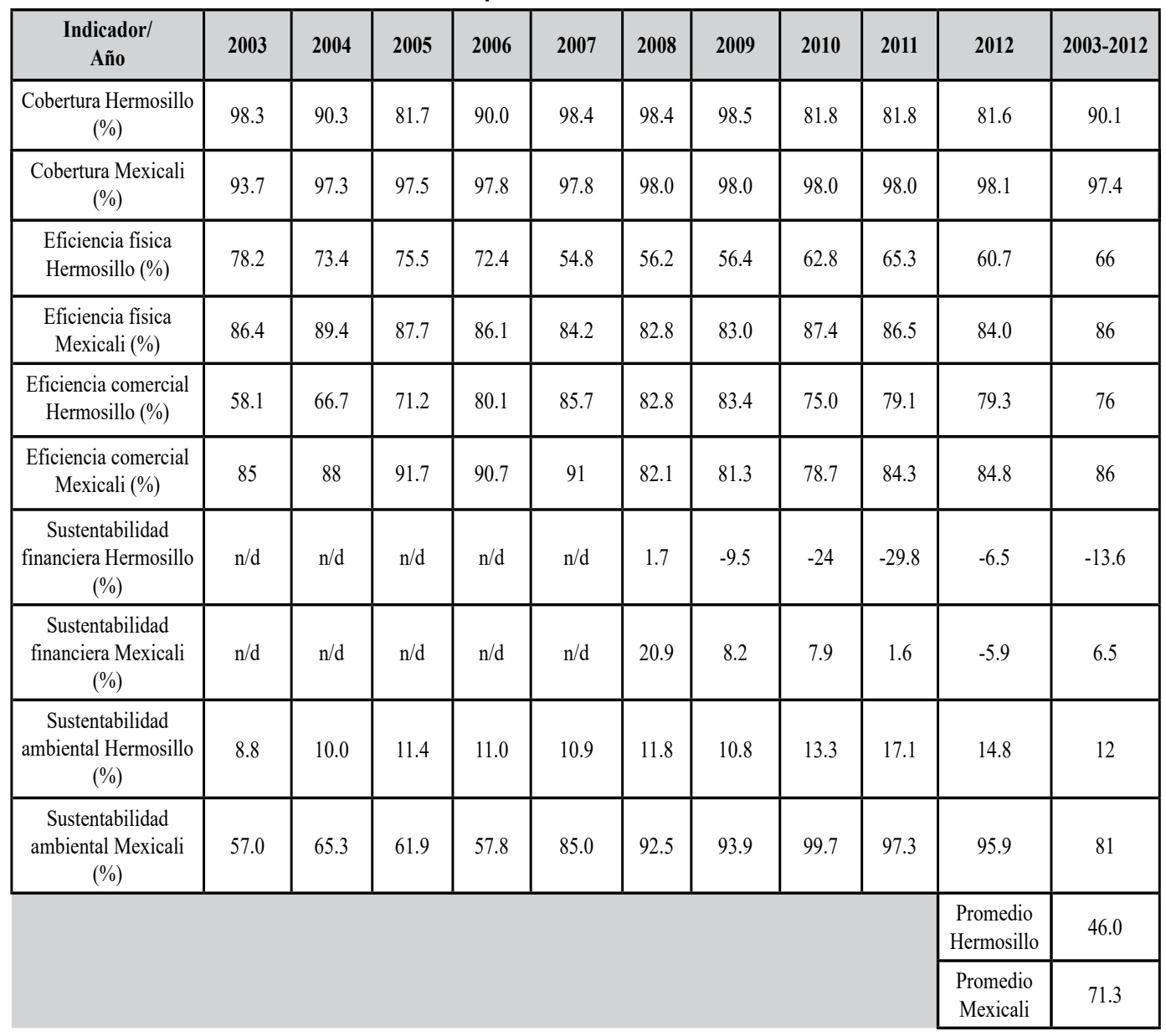

Fuente: Elaboración propia con información del Programa de Indicadores de Gestión de Organismos Operadores (PIGOO) (s.f.), Agua de Hermosillo (s.f.) y CESPM (s.f.).

\section{Cobertura y continuidad en el servicio de agua}

Una de las prioridades de los OoA es dotar de agua de manera continua a la población y recolectar las aguas residuales. Hermosillo tiene una amplia cobertura del sistema de drenaje y agua potable, sin embargo, en los últimos años ha enfrentado serios problemas para satisfacer la demanda continua de agua, la cual se cubre mediante la extracción de agua de fuentes subterráneas principalmente. En el periodo 2004-2006 
se implementó por primera vez el sistema de tandeos de agua ${ }^{2}$ en varios sectores de la ciudad y durante el periodo 2003-2012, solo $75 \%$ de las tomas tuvieron servicio continuo (en promedio). En Mexicali, el agua potable proviene del río Colorado y se suministra el servicio los siete días de la semana sin interrupciones. En el desempeño de cobertura, Hermosillo tiene $90 \%$ mientras que Mexicali supera $97 \%{ }^{3}$

\section{Eficiencia física y comercial}

La eficiencia física ${ }^{4}$ nos indica qué porcentaje del agua producida es efectivamente suministrado a la población, una vez descontados los volúmenes de agua que se pierden en el sistema de distribución, ya sea por fugas o por robo. La eficiencia física de Hermosillo y Mexicali contrastan significativamente. El indicador para Agua de Hermosillo en el periodo fue de 66\% mientras que para la CESPM en el periodo 20032012, el promedio fue de $86 \%$ de eficiencia física. Una de las razones por las que se tienen altas pérdidas de agua en Hermosillo es por el poco control que se tiene sobre los volúmenes de agua que ingresan y se distribuyen en la red de agua potable. La macromedición (es decir, el porcentaje de fuentes de producción de agua que cuentan con medidor) de Agua de Hermosillo fue de $61 \%$ y desde del año 2003 en adelante no se observó ninguna mejoría, sino un retroceso, pues en el 2012, la macromedición fue de $38 \%$. La micromedición (porcentaje de usuarios con medidor) también presenta problemas pues en el año 2012 existía un déficit de micromedidores de $25 \%$. Además, de las 186788 viviendas con medidor instalado, solamente se le tomó lectura a $67 \%$, principalmente por la subutilización del recurso humano, es decir, implementaron una política de compra de medidores, pero no reestructuraron las rutas para la medición. En contraste, en Mexicali la macro y micromedición se hacen prácticamente a $100 \%$.

La eficiencia comercial, es el porcentaje del volumen recaudado con respecto al volumen facturado. Para mantener un buen desempeño en este rubro se requiere de la combinación tanto de elementos técnicos como políticos. La CESPM generalmente planifica bien sus acciones, su micromedición es alta, y regularmente depura su padrón de usuarios, además, el equipo para tomar lecturas y facturar es efectivo. Hasta aquí, tienen los ingredientes para alcanzar una alta eficiencia comercial. Sin embargo, la política de cobranza incide en la morosidad y la cartera vencida (Véase Tabla 2), por

\footnotetext{
${ }^{2}$ Suspensión periódica del agua por intervalos de tiempo durante el día.

${ }^{3}$ Aparentemente, la cobertura y servicio continuo se encuentra directamente relacionada con fuentes de abastecimiento, sin embargo, también tiene que ver con la planificación del recurso y el uso eficiente del mismo. Un breve análisis de sus planes y programas permite observar, que en Hermosillo, desde el Plan Municipal de Desarrollo de Hermosillo 2000-2003 (Infomex, Solicitud de información nro. 00660514) sigue repitiendo el mismo diagnóstico y proponiendo las mismas políticas las cuales se resumen en la escasez de agua, la construcción de una gran obra para satisfacer la demanda de la ciudad, así como el reciclamiento de aguas residuales. Sin embargo, es hasta el periodo de gobierno estatal 2009-2015 cuando se discutió y aprobó (periodo en el que coincidieron gobernantes en los tres niveles de gobierno del mismo partido político) la implementación de un acueducto para satisfacer la demanda de agua de la ciudad, el cual hasta el momento, enfrenta demandas pendientes de resolución en la Suprema Corte de Justicia de la Nación (Véase a Moreno, 2015). Para Baja California, revisando los planes y programas del gobierno estatal, se observan avances y diferentes propuestas de un periodo a otro.

${ }^{4}$ Eficiencia física (EF): EF= (Volumen facturado / Volumen producido) $\times 100$.
} 
lo que $86 \%$ en su eficiencia comercial solo se explica por las frecuentes políticas de condonación en multas, recargos y adeudos. ${ }^{5}$

Tabla 2: Morosidad en Hermosillo y Mexicali en el periodo 2003-2012 (\%)

\begin{tabular}{|c|c|c|c|c|c|c|c|c|c|c|c|}
\hline $\begin{array}{c}\text { Indicador/ } \\
\text { Año }\end{array}$ & $\mathbf{2 0 0 3}$ & $\mathbf{2 0 0 4}$ & $\mathbf{2 0 0 5}$ & $\mathbf{2 0 0 6}$ & $\mathbf{2 0 0 7}$ & $\mathbf{2 0 0 8}$ & $\mathbf{2 0 0 9}$ & $\mathbf{2 0 1 0}$ & $\mathbf{2 0 1 1}$ & $\mathbf{2 0 1 2}$ & $\mathbf{2 0 0 3 -}$ \\
\hline $\begin{array}{c}\text { Pago a } \\
\text { tiempo } \\
\text { Hermosillo }\end{array}$ & 64.0 & 74.5 & 74.4 & 72.2 & 75.4 & 72.8 & 72.5 & 75.5 & 73.1 & 73.4 & 73 \\
\hline $\begin{array}{c}\text { Pago a } \\
\text { tiempo } \\
\text { Mexicali }\end{array}$ & 19.0 & 18.2 & 17.1 & 16.2 & 16.6 & 15.7 & 15.9 & 16.4 & 17.0 & 17.2 & 17 \\
\hline
\end{tabular}

Fuente: Propia con información de PIGOO (s.f.), Agua de Hermosillo (s.f.) y CESPM (s.f.).

Hermosillo tiene problemas con la medición de agua, su padrón de usuarios no es confiable (actualmente el padrón se encuentra en depuración) y si bien poseen la infraestructura y tecnología para facilitar la facturación y recaudación, la falta de planeación para dar seguimiento al reporte de fallas y la mala planeación en el diseño de rutas para la medición de consumos y entrega de recibos, han contribuido a su baja eficiencia comercial. Por otra parte, en el periodo registran un pago a tiempo de $73 \%$, el cual es alto, considerando las 70270 quejas que por motivo de mala facturación se presentaron en el año 2012. Además, tiene déficit en la gestión de la cobranza. El promedio anual en eficiencia comercial del periodo para Hermosillo fue de $76 \%$, mientras que en Mexicali fue de $86 \%$.

\section{Sustentabilidad financiera}

En la evaluación de la sustentabilidad financiera, solamente se recabó información para el periodo 2008-2012. De acuerdo con los datos en la Tabla 1, Hermosillo tradicionalmente trabaja en números rojos, aunque en el último año presentó una leve mejoría al registrar un déficit de solamente $6.5 \%$, cuando un año antes fue casi de $30 \%$. La operación deficitaria de Hermosillo se deriva de los bajos niveles de eficiencia con que opera, pues sus altas pérdidas de agua incrementan los costos de operación, mientras que la baja recaudación incide de forma negativa en los ingresos.

En el año 2008 Mexicali tuvo un superávit de 20\%, pero en los siguientes tres años fue descendiendo para culminar en déficit en el año 2012. Esta situación se explica por tres factores, primero, el pago de los créditos se incrementó; segundo, el terremoto que afectó al municipio en el año 2010 provocó que recursos que estaban programados para el organismo se reasignaran a otras áreas; y tercero, las frecuentes políticas de condonación de recargos, multas y adeudos implementadas por el gobierno del estado han minado los ingresos de la paraestatal.

${ }^{5}$ Según el Decreto del Ejecutivo del Estado, mediante el cual se condona a los usuarios (2014, pp. 4-5):

Se condona a los usuarios del servicio doméstico el 100\% (cien por ciento) del pago de las contribuciones omitidas por concepto de derechos por consumo de agua (...), así como el $100 \%$ (cien por ciento) de los recargos y multas provenientes de dichas contribuciones, por los servicios que prestan las Comisiones de Servicios Públicos en el Estado que se hayan generado hasta el 31 de diciembre de 2012. 


\section{Sustentabilidad ambiental}

Desde su creación en el año 2002, Agua de Hermosillo manifestó la intención de construir plantas de tratamiento de aguas residuales, sin embargo, hasta el año 2012 seguía siendo un pendiente. Por su parte, La CESPM, tiene más de una década trabajando en el tratamiento de aguas residuales, en el año 2003 trataba un poco más de $50 \%$, pero a partir del 2009 trata casi todo el agua que recolecta. Sin embargo, el drenaje y alcantarillado en el año 2011 era de $83.5 \%$, lo cual indica que no todas las aguas residuales que se generan en la ciudad son tratadas.

De acuerdo al desempeño presentado por los dos organismos, en donde el de Mexicali tiene mejores resultados, surge la pregunta sobre ¿Existen grandes diferencias entre el SGRH de la CESPM respecto al de Agua de Hermosillo? ¿Cuáles son las características de los dos SGRH y qué prioridad tiene para los organismos establecer sistemas de gestión de personal de carácter meritorio? ¿Se ven reflejadas las prácticas y la configuración de los SGRH en el desempeño?

\section{Características de los Sistema de Gestión de Recursos Humanos del sector público en México y el mundo}

El término "patrimonialismo" fue acuñado por Max Weber para describir situaciones en donde el personal directivo y administrativo de un organismo es nombrado por un líder supremo (denominado patrón) y responde únicamente a este (Brinkerhoff y Goldsmith, 2002). En países latinoamericanos distintos estudios (Grindle, 1977; Mansilla, 1991; Oszlak, 1980; Roth, 1968) advierten características patrimonialistas en el ejercicio del poder político, lo que significa que los funcionarios deben su permanencia y lealtad a la persona que los designó por lo que el gobernante decide arbitrariamente tanto el diseño de la estructura jerárquica como el personal que ocupará cada uno de los puestos. En una estructura patrimonialista los incentivos de los funcionarios están alineados con los intereses políticos de su patrón y no con los de la organización en donde laboran, afectando al desempeño.

Las prácticas patrimonialistas se producen cuando existen condiciones para la discrecionalidad política en el manejo de los SGRH. Meyer-Sahling (2004), define un bajo nivel de discrecionalidad política como aquel en donde la estructura del servicio civil hace virtualmente imposible que los gobiernos interfieran en los asuntos concernientes al SGRH de la administración pública, el cual se encuentra bajo la autoridad de actores administrativos e independientes que operan bajo una densa red de reglas, procedimientos y estándares que aseguran la profesionalización del servicio público.

Con el fin de fomentar el establecimiento de un SGRH de carácter meritorio en la región, en el año 2003 el Centro Latinoamericano de Administración para el Desarrollo (CLAD) y el Departamento de Asuntos Económicos y Sociales de las Naciones Unidas, dieron a conocer la Carta Iberoamericana de la Función Pública, entre otras finalidades para "definir las bases que configuran un sistema profesional y eficaz de función pública, entendiendo a este como una pieza clave para la gobernabilidad democrática de las sociedades contemporáneas, y para la buena gestión pública" 
(Carta Iberoamericana de la Función Pública, 2003, p. 5). ${ }^{6}$ El documento exhorta a evitar patrimonializar la administración implementando medidas que garanticen independencia e imparcialidad en los nombramientos y el desarrollo de las actividades de los funcionarios.

El gobierno mexicano no ha permanecido inerte a estas iniciativas y ha tratado de modernizar y configurar un SGRH eficaz y eficiente. Sin embargo, los resultados no han sido los esperados ya que ha faltado claridad para identificar tanto los objetivos como los medios para lograrlo. En este sentido, las reformas de los años setenta se encaminaron a profesionalizar la burocracia, mientras que la de los ochenta se enfocó en el ahorro de recursos obtenido de la supresión de personal de la nómina estatal (Oszlak, 2002). Asimismo, hay que agregar que tradicionalmente México se ha distinguido por la rotación permanente del personal de confianza tras cada proceso electoral. ${ }^{7}$

En los años noventa se emprendieron cambios para mejorar la competitividad de las empresas a través de la flexibilidad en el trabajo, por lo que las empresas paraestatales (sobre todo aquellas que estaban en proceso de privatización) fueron las que tuvieron cambios más profundos en sus CCT, dando paso hacia la flexibilidad laboral.

Temas comunes de flexibilidad contractual en estas plantas son: libertad a la gerencia para emplear trabajadores eventuales o usar subcontratistas; libertad para contratar trabajadores de confianza; movilidad interna de los trabajadores; reducción del escalafón y ampliación de las funciones de los puestos; promoción no por antigüedad sino por desempeño o capacitación (Garza, 2003, p. 2).

Si bien, estas políticas surgieron como una respuesta al poder de los sindicatos, ${ }^{8}$ las nuevas propuestas pretendían proveer a la administración facultades para diseñar modelos de gestión de carácter meritorio, pero sobre todo, buscando proteger el beneficio de la administración. En este sentido, las principales medidas que tomaron los organismos para reducir sus déficit financieros fue la de reducir el número de empleados por cada 1000 tomas. De esta manera, Agua de Hermosillo redujo este indicador de 4.4 en el 2003 a 3.4 en el año 2012, mientras que en la CESPM la reducción fue de 5.25 a 3.49 en los mismos años, ${ }^{9}$ este ajuste como se observa, fue mayor para el organismo de Mexicali.

Otra visión en la gestión de recursos humanos resalta la importancia de dar estabilidad laboral al personal, abogando por alcanzar acuerdos de reciprocidad entre

\footnotetext{
${ }^{6}$ Aprobada por la $\vee$ Conferencia Iberoamericana de Ministros de Administración Pública y Reforma del Estado. Respaldada por la XIII Cumbre Iberoamericana de Jefes de Estado y de Gobierno (Resolución N ${ }^{\circ}$ 11 de la "Declaración de Santa Cruz de la Sierra") Bolivia, 14-15 de noviembre de 2003.

${ }^{7}$ En la década de los años setenta un estudio realizado por Marilee Grindle (1977) documentó esta situación, que si bien se avoca a analizar la relación clientelar entre patrón-empleados que se genera en la esfera federal como producto del cambio sexenal, también sirve para ejemplificar lo que ocurre en la elección de gobernadores y presidentes municipales.

${ }^{8}$ Ya que antes de las reformas en los años noventa el sistema de gestión que imperó en las organizaciones públicas se caracterizaron por la presencia de un sindicato "fuerte", que buscaba para sus agremiados o líderes sindicales la mayor cantidad de beneficios pero sin el compromiso de incrementar el desempeño del trabajador.

${ }^{9}$ Aboites, Birrichaga y Garay (2010) señalan que un cambio sustancial generado de las reformas de 1982 se cristalizó en 1985 a través de una reforma fiscal, el gobierno federal restringe el gasto en materia de agua potable y alcantarillado e incrementa los precios por el uso del agua.
} 
la empresa y los sindicatos con el fin de diseñar estrategias que satisfagan tanto a los intereses de la empresa como a los de los trabajadores (Camacho, 2014). Un estudio publicado por el Banco Interamericano de Desarrollo (BID) coincide con esta postura al señalar que:

La función de la gestión de recursos humanos tiene a su cargo la planificación y el control de los recursos humanos para asegurarse que se satisfagan las necesidades de las personas de modo que puedan trabajar para lograr las metas de la organización (Lusthaus, Adrien, Anderson, Carden y Plinio, 2002, p. 61).

Esta propuesta aboga por construir un sistema adecuado de gestión en donde, al priorizar la satisfacción de las necesidades de los empleados, simultáneamente prioriza el cumplimiento de los objetivos de la organización. En el año 2003 se promulga en nuestro país la Ley de Servicio Profesional de Carrera pero solamente es válida para la administración pública federal, por ello, el rezago y los malos hábitos aún persisten y son más visibles en el ámbito local, que es en donde se desarrolla la gestión del agua potable en México.

Fuera del ámbito latinoamericano también se han llevado a cabo reformas importantes en los SGRH del sector público, con resultados mixtos. Moon y Hwang (2013) hicieron un estudio comparativo del servicio civil de carrera en una muestra de países de la región Asia-Pacífico, en donde observaron que los esfuerzos para reformar el servicio civil han estado orientados hacia la reducción de personal, la flexibilización de la contratación, incentivos al desempeño y el combate a la corrupción. La mayor parte de estos países cuenta con exámenes y sistemas meritocráticos para el acceso al servicio civil, sin embargo persisten prácticas de corrupción y patrimonialismo, especialmente en países del sureste asiático (Indonesia, Malasia, Filipinas y Tailandia), así como en aquellos que transitaron del socialismo hacia una economía de mercado (China, Vietnam y Camboya), que no contaban con un marco legal para el servicio civil previo a la transición. Los problemas para establecer SGRH desvinculados de la discrecionalidad política en los países excomunistas también ha sido documentada para el caso de Europa oriental, en donde Meyer-Sahling (2004) encontró que a pesar de la transición persistían los mecanismos discrecionales de ingreso al sector público, que habían sido utilizados durante el régimen comunista como un medio para asegurarse de que los servidores públicos eran leales al gobierno y su ideología. Los nuevos gobiernos surgidos de la transición desconfiaban de los burócratas de los gobiernos comunistas y preferían reclutar al personal de entre sus propias redes políticas, lo que ha provocado que los intentos de reforma del servicio civil en estos países no hayan tenido los resultados esperados.

En el caso de los organismos de agua potable Tortajada (2006) indica que los OOA fallan en sus SGRH debido principalmente a:

1. Prácticas patrimonialistas, ya que el personal es contratado debido a sus conexiones políticas en lugar de su capacidad técnica, lo que conlleva a su vez a un incremento excesivo del personal.

2. Baja remuneración que impide contratar y conservar en el organismo a los mejores elementos y genera un ambiente propicio para la corrupción.

3. Incrementos salariales y ascensos basados en antigüedad y conexiones políticas en vez del mérito.

Además, señala que estos problemas son comunes en la mayoría de los oOA en todo el mundo (Tortajada, 2006). No obstante, hay organismos excepcionales, como es el caso de Singapur (uno de los ooA más eficientes del mundo), en donde se cuenta 
con incentivos comparables a los de las empresas privadas, se proveen incentivos a la mejora en el desempeño y existe un compromiso importante con la capacitación del personal. Además existen estrictos controles y mecanismos de transparencia para evitar la corrupción.

Como parte de la experiencia de los países asiáticos vale la pena mencionar el caso de Phnom Pehn, capital de Camboya. Durante la dictadura comunista (19791993) miles de habitantes de esta ciudad fueron desalojados y forzados a trabajar en el campo. Cuando terminó la dictadura, mucha gente regresó a una ciudad con una infraestructura hidráulica en ruinas. El ooA operaba con altas pérdidas de agua y tenía muy bajos niveles de cobranza. En 1992, el primer ministro del país nombró como director del ooA a Ek Son Chan, quien gozó de plena autonomía para tomar decisiones, por lo que no tuvo la presión para llevar a cabo nombramientos con base en criterios políticos. Chan llevó a cabo una depuración del personal corrupto y generó incentivos para el personal que permaneció en el organismo. Esta política tuvo gran impacto en el aumento de la cobranza en el organismo, dado que la recaudación llegaba al ooA en vez de a los bolsillos de los recaudadores despedidos, mientras que los recaudadores que permanecieron en el ooA obtuvieron bonos por su eficiencia que los colocaba en un nivel de ingreso muy atractivo para la región (Biswas y Tortajada, 2009).

\section{El Sistema de Gestión de Recursos Humanos en los organismos de Agua de Hermosillo y Comisión Estatal de Servicios Públicos de Mexicali}

En la literatura sobre la gestión de personal se mencionan distintos atributos que se deben contemplar para definir un sistema de recursos humanos ${ }^{10}$ de carácter meritorio, ${ }^{11}$ pero ante la imposibilidad de revisarlos todos, para el desarrollo de este trabajo se seleccionaron los siguientes: 1) Políticas de contratación de personal, 2) Desarrollo y capacitación, 3) Salario, prestaciones y estímulos y 4) Sanciones.

\footnotetext{
${ }^{10}$ Según Lusthaus et al. (2002) "La gestión de los recursos humanos comprende la planificación, ejecución y supervisión de la fuerza laboral de la organización". Para Longo (2004, p. 4):

La gestión de recursos humanos (GRH) es presentada como un sistema integrado de gestión, cuya finalidad básica o razón de ser es la adecuación de las personas a la estrategia de una organización o sistema multiorganizativo, para la producción de resultados acordes con las finalidades perseguidas.
}

Para este estudio, definimos por SGRH: El conjunto de reglas y procedimientos dirigidos a diseñar e implementar las políticas de contratación, selección, salarios, prestaciones, desarrollo y sanciones orientados a cubrir tanto las necesidades del personal como el cumplimiento de los objetivos de la organización.

${ }^{11}$ Lusthaus et al. (2002) revisa cinco apartados para establecer un SGRH eficiente: planificación, dotación de personal, desarrollo, evaluación y recompensas, y mantenimiento de relaciones efectivas. Asimismo, la Carta Iberoamericana de la Función Pública (2003). establece una multitud de criterios y principios rectores por considerar para construir un modelo de GRH de carácter meritorio, entre ellos los que aquí se estudian. 


\section{Políticas de contratación del personal}

Los empleados que laboran en los ooA de Hermosillo y Mexicali se clasifican principalmente, en dos tipos: sindicalizados y de confianza ${ }^{12}$ y para cada uno de ellos, el marco jurídico establece los lineamientos que regulan las relaciones laborales entre trabajador-organismo.

\section{Políticas generales para la contratación del personal de confianza}

En el año 2012 la planta laboral de Agua de Hermosillo se conformaba por 213 empleados de confianza (23\%) y 708 sindicalizados para un total de 921 empleados. Respecto al perfil de puestos, el artículo 65 del Reglamento Interior de Agua de Hermosillo (2013, p. 26), estipula que "el Director General, los directores, coordinadores, gerentes, administradores, jefes de departamento, asesores y demás personal que efectúe labores de inspección, vigilancia y manejo de fondos son trabajadores de confianza".

El personal de confianza es el responsable de guiar el desarrollo del organismo, por lo que la selección de personal capacitado debería ser la norma, sin embargo, el nombramiento de ellos, al igual que las personas que ocupan los puestos de mayor jerarquía, frecuentemente responde a intereses ajenos a la paramunicipal, es decir, algunos son representantes del gobierno del estado y otros del municipio, por lo que el margen para que el director pueda designar personal calificado es muy restringido. ${ }^{13}$

Dentro de los puestos considerados de confianza, tan solo al director general y al comisario del organismo se les exige tener conocimientos previos y un perfil acorde al trabajo a desempeñar, aunque el director del periodo 2012-2015 no cumplía con estos requisitos. Además, cada tres años se da una alta tasa de rotación en el área administrativa, por ejemplo, del personal de confianza que laboró en el periodo 20092012 solamente 43\% continuó en el organismo en el periodo 2012-2015 aún y cuando se mantuvo el mismo partido en el poder. ${ }^{14}$

\footnotetext{
12 De acuerdo con el artículo 154 de la Ley Federal del Trabajo (1970), "se entiende por sindicalizado a todo trabajador que se encuentre agremiado a cualquier organización sindical legalmente constituida" mientras que según el artículo 9 "la categoría de trabajador de confianza depende de la naturaleza de las funciones desempeñadas y no de la designación que se dé al puesto. Son funciones de confianza las de dirección, inspección, vigilancia y fiscalización, cuando tengan carácter general, y las que se relacionen con trabajos personales del patrón dentro de la empresa o establecimiento."

${ }^{13}$ Durante una plática en el Colegio de Sonora, Hermosillo, el exmiembro del Consejo Consultivo del Agua manifestó lo siguiente:

Revisando el organigrama me senté con (el Director del Organismo para el periodo 2006-2010) y cuadrito por cuadrito fuimos analizando. ¿Y éste, cómo llegó aquí? Este es recomendado por fulano de tal. (...) Y la gente que está abajo del director general y después, ya que terminamos, le digo: ya sé que éste trabaja para el alcalde, éste para el secretario de gobierno, éste trabaja para fulanito diputado, este para determinado (no se entiende). Ya tenía un mapa correcto de los padrinos de cada uno. ¿Y para Agua de Hermosillo, quién trabaja?
}

\footnotetext{
${ }^{14}$ Información recuperada desde el Directorio telefónico de la administración pública municipal 2006-2009 del H. Ayuntamiento de Hermosillo 2006-2009; el Directorio del personal de confianza 2009-2012; y la Solicitud de información a Agua de Hermosillo núm. 00111615 del 9 de marzo de 2015 vía Infomex (se
} 
Por otra parte, el Reglamento Interno de la Comisión Estatal de Servicios Públicos de Mexicali (2007) no establece explícitamente los puestos que son considerados de confianza ni las capacidades que deben poseer las personas asignadas a ellos, pero en su redacción permite entrever que coincide con los de Agua de Hermosillo. En este caso, los puestos de confianza son el director general, subdirectores, jefes de departamento y titulares de las Unidades de Apoyo. El nombramiento del personal de confianza lo realizan el titular del poder ejecutivo de Baja California y las altas autoridades del organismo. Al depender del poder ejecutivo estatal los nombramientos se realizan por un periodo de seis años, aunque en el periodo de gobierno 2007-2013 en cuatro ocasiones ${ }^{15}$ se removió al titular del organismo y en la actual administración ya van dos directores, lo que también incide en la rotación del personal de confianza. De 33 personas con puestos directivos en el año 2011, solamente 58\% continuaban laborando en la CESPM en el año 2015, aún y cuando se mantiene el mismo partido en el poder (PAN). Además, de 1271 personas que laboraban en el año 2012, 55\% correspondían a empleados de confianza, ya que a diferencia de Agua de Hermosillo, muchos de ellos son contratados para ejecutar tareas operativas. ${ }^{16}$ En términos generales, en los dos organismos existen altos niveles de discrecionalidad política por parte de los titulares del poder ejecutivo, lo que impide que se garantice la permanencia del personal que toma las decisiones más importantes.

\section{Políticas de contratación del personal de base}

El personal de base de ambos organismos se encuentra adscrito a sindicatos quienes son los responsables de negociar ante los directivos de los oOA los beneficios de los trabajadores agremiados a través de los ССт. Los empleados de base del ooA de Hermosillo se encuentran adscritos al Sindicato de Agua de Hermosillo el cual se encuentra afiliado a la Confederación de Trabajadores de México (Contrato Colectivo de Trabajo 2012, 2012); por otra parte, los trabajadores sindicalizados de la CESPM pertenecen al Sindicato Único de Trabajadores al Servicio de los Poderes del Estado, Municipios e Instituciones Descentralizadas de Baja California, Sección Mexicali (Contrato Colectivo de Trabajo 2012-2013, 2012).

En el caso de Hermosillo cuando requiere de trabajadores eventuales o de tiempo fijo, lo solicita al sindicato y este dispone de cinco días hábiles para proponer a los candidatos, en caso de no presentarlos, el organismo puede contratar libremente a la persona que considera pertinente para el puesto, con la condición de que en un plazo de ocho días solicite su ingreso al sindicato (Contrato Colectivo de Trabajo 2012, 2012, pp. 2-3). También se estipula que los trabajadores que proporcione el sindicato deberán cumplir con los requisitos contenidos en el Manual de descripción de puestos y serán sujetos a un periodo de prueba no mayor de 30 días para evaluar sus aptitudes. En caso de no satisfacer las expectativas serán sometidas a evaluación por peritos designados tanto por la empresa como por el sindicato.

\footnotetext{
realizó una comparación de los empleados de confianza entre los dos periodos de gobierno).

${ }^{15}$ Aunque Francisco Javier Orduño Valdez ocupó el puesto de director general en dos ocasiones, 20072008 y 2012-2013.

${ }^{16}$ CESPM a través de la Solicitud de información Folio-UCT-152805 del 27 de agosto de 2015 vía Infomex. Además se constató la permanencia del personal con la revisión de la plantilla del personal de 2015.
} 
En Mexicali opera un criterio similar para la contratación de personal de nuevo ingreso, que no es de confianza, con la diferencia de que el sindicato dispone de un plazo máximo de quince días para proporcionar al candidato al área de recursos humanos con la condición de que cumplan con el perfil requerido para el puesto. ${ }^{17}$ En caso contrario, el organismo puede realizar la contratación con la condición de solicitar posteriormente su afiliación al Sindicato (Contrato Colectivo de Trabajo 20122013, 2012, cláusula vigésima sexta).

Los mecanismos empleados para la contratación de personal de base interfieren en la capacidad de los organismos para seleccionar a las personas idóneas para ocupar los puestos vacantes ya que se limita a las propuestas hechas por los sindicatos. Estas medidas afectan a las áreas responsables de la gestión de recursos humanos de los organismos al inhibir la posibilidad de implementar estrategias novedosas para seleccionar personal calificado afectando, además, la profesionalización de la planta laboral.

\section{Desarrollo y capacitación}

Otro mecanismo clave para incrementar la capacidad administrativa está relacionada con el sistema de capacitación, ${ }^{18}$ desarrollo y estímulos que una organización pueda ofrecer a sus colaboradores, en el entendido que entre mayor sea el interés por identificar las necesidades de aprendizaje de los trabajadores, proporcionar estímulos para reducir la rotación y ofrecer oportunidades para desarrollar sus recursos humanos, mayor será la posibilidad de profesionalizar el aparato burocrático.

\section{Capacitación y desarrollo en Agua de Hermosillo}

El Reglamento Interior de Trabajo de Agua de Hermosillo (2013) define las políticas de capacitación y las liga directamente con la productividad. El organismo tiene la responsabilidad de implementar programas de capacitación tanto para desarrollar las aptitudes de los trabajadores, con el fin de prepararlos para ocupar puestos de mayor nivel, como para prevenir los riesgos de trabajo y elevar la productividad. Esta tarea se encuentra delegada a la Dirección de Recursos Humanos (DRH), (Manual de Organización de Agua de Hermosillo, 2011).

Formalmente, el Departamento de Desarrollo Organizacional y Capacitación (DDOC) a través de la Detección de Necesidades de Capacitación (DNC) identifica las áreas que se necesitan fortalecer y selecciona al personal que requiere entrenamiento

\footnotetext{
${ }^{17}$ Manuel Guerrero, delegado sindical de la CESPM, manifestó durante una entrevista el 27 de enero de 2014 que últimamente la CESPM contrataba directamente sin hacer el trámite correspondiente con el sindicato.

${ }^{18}$ Según Chiavenato (2007, p. 386):

La capacitación es el proceso educativo de corto plazo, aplicado de manera sistemática y organizada, por medio del cual las personas adquieren conocimientos, desarrollan habilidades y competencias en función de objetivos definidos. La capacitación entraña la transmisión de conocimientos específicos relativos al trabajo, actitudes frente a aspectos de la organización, de la tarea y del ambiente, así como desarrollo de habilidades y competencias.
} 
(Programa Operativo Anual [POA] 2013). ${ }^{19}$ La DNC surge de la premisa de que existe un déficit entre las capacidades que se requieren para la ejecución de una tarea y las aptitudes que posee un trabajador. Sin embargo, en la Tabla 3 se observa que no hay seguimiento al programa de capacitación ya que de las 13 actividades señaladas en el $\mathrm{POA}^{20}$ tan solo en cuatro de ellas se ejecutó (más o menos) $20 \%$ de lo programado.

Tabla 3: Actividades de capacitación implementadas por Agua de Hermosillo 2009-2013 a través de los Programas Operativos Anuales

\begin{tabular}{|c|c|c|c|c|c|c|}
\hline \multicolumn{4}{|c|}{ Programa Operativo Anual 2009-2013 } & \multicolumn{3}{|c|}{ Metas anuales } \\
\hline Año & Descripción & Unidad responsable & $\begin{array}{l}\text { Unidad de } \\
\text { medida }\end{array}$ & Programado & Ejecutado & $\begin{array}{c}\% \text { de } \\
\text { cumplimiento }\end{array}$ \\
\hline 2013 & $\begin{array}{l}\text { Asistencia a diferentes } \\
\text { eventos de capacitación }\end{array}$ & $\begin{array}{c}\text { Auditoría } \\
\text { Administrativa } \\
\end{array}$ & Curso & 8 & 14 & 175 \\
\hline 2013 & $\begin{array}{l}\text { Asistencia a diferentes } \\
\text { eventos de capacitación }\end{array}$ & Auditoría en Obras & Evento & 5 & 5 & 100 \\
\hline 2013 & $\begin{array}{l}\text { Cumplir con acciones de } \\
\text { capacitación y certificación } \\
\text { de personal de sistemas }\end{array}$ & Sistemas & Certificado & 11 & 1 & 9 \\
\hline 2013 & Programa de capacitación & Recursos Humanos & Informe & 26 & 27 & 104 \\
\hline 2013 & $\begin{array}{l}\text { Diagnósticos de } \\
\text { necesidades de capacitación }\end{array}$ & Recursos Humanos & Informe & 3 & 2 & 67 \\
\hline 2012 & $\begin{array}{l}\text { Programar cursos de } \\
\text { capacitación con base en } \\
\text { recursos autorizados }\end{array}$ & Recursos Humanos & $\mathrm{Hr} / \mathrm{Hom} / \mathrm{Ca}$ & 4 & 1.5 & 38 \\
\hline 2012 & $\begin{array}{l}\text { Asistir a diferentes tipos de } \\
\text { capacitación }\end{array}$ & $\begin{array}{c}\text { Auditoria } \\
\text { Administrativa } \\
\end{array}$ & Revisión & 1 & 12 & 1200 \\
\hline 2012 & $\begin{array}{l}\text { Asistir a diferentes tipos de } \\
\text { capacitación }\end{array}$ & Auditoría en obras & Evento & 3 & 6 & 200 \\
\hline 2011 & $\begin{array}{l}\text { Capacitar al personal que } \\
\text { atiende al usuario }\end{array}$ & Of. Com. & Persona & 343 & 193 & 56 \\
\hline 2011 & Programa de capacitación & Recursos Humanos & Evento & 12 & 11 & 92 \\
\hline 2010 & $\begin{array}{l}\text { Capacitar al personal que } \\
\text { atiende al usuario }\end{array}$ & Of. Com. & Persona & 40 & 0 & 0 \\
\hline 2010 & $\begin{array}{l}\text { Realizar diagnóstico de } \\
\text { DNC }\end{array}$ & Recursos Humanos & Documento & 1 & 1 & 100 \\
\hline 2010 & $\begin{array}{l}\text { Cursos y talleres de } \\
\text { capacitación }\end{array}$ & Recursos Humanos & Curso & 0 & 0 & $\mathrm{n} / \mathrm{a}$ \\
\hline 2009 & $\begin{array}{l}\text { Realizar diagnóstico de } \\
\text { DNC }\end{array}$ & Recursos Humanos & Documento & 1 & 0 & 0 \\
\hline
\end{tabular}

Fuente: Elaboración propia con datos del Instituto de Transparencia Informativa del Estado de Sonora (Ities) (2017).

\footnotetext{
${ }^{19}$ Esta actividad la realiza el Departamento de Capacitación.

${ }^{20}$ Según el Instructivo para la Formulación de los Programas Operativos Anuales 2015 (2014, p. 4):
}

Los Programas Operativos Anuales son el instrumento programático presupuestal para la ejecución del plan y programas de desarrollo; rigen las actividades de la administración pública durante el año respectivo, estableciendo objetivos, indicadores y metas, y sirven de base para la formulación de los Proyectos de Presupuesto. 
Estas fallas no son exclusivas del DDOC ya que las distintas áreas que programan actividades de capacitación tampoco cumplieron con el programa. Por ejemplo, en el año 2013, la Auditoría Administrativa programó ocho cursos de capacitación y realizó 14, el área de Sistemas programó 11 actividades aunque finalmente ejecutó una, asimismo, se programó la capacitación de 40 personas que atienden directamente a los usuarios y no se capacitó a ninguna. Esta información ayuda a explicar el porqué los empleados de Agua de Hermosillo no están preparados para atender a los usuarios. El área de sistemas programó 11 certificaciones y cumplió solo con una, mientras la Auditoría en Obras programó y ejecutó cinco eventos de capacitación (POA, 2013).

Por otra parte, en el portal de transparencia del organismo, en el apartado Sistema de Gestión por Comparación, la Comisión Estatal de Agua de Sonora (CEAsOn) pone a disposición de Agua de Hermosillo distintos cursos, indicándole el número de empleados que pueden asistir, sin embargo, el organismo no tiene un registro del personal que asiste a esos cursos, lo cual indica que no se da seguimiento a la capacitación del personal, por lo que no está claro de qué manera el organismo vincula la capacitación con la productividad o con base en qué criterios se diseñan los programas con las necesidades que realmente requiere el personal.

Respecto al desarrollo, el CCT señala que los puestos vacantes o un ascenso, se cubren conforme al Reglamento de la Comisión Mixta de Escalafón, estableciendo que el trabajador se someterá a un periodo de prueba de 30 días para demostrar sus aptitudes (Contrato Colectivo de Trabajo 2012, 2012, p. 3). Con estas medidas, formalmente se pretende vincular la capacitación con el desarrollo, para lo cual también es necesario programar los cursos que requieren los empleados y planificar los tiempos para que puedan asistir, pero sin descuidar el desarrollo de las actividades que cotidianamente realizan. En la Tabla 4 se agrupó en cinco temáticas la capacitación que recibió el personal en el periodo 2011-2013.

Tabla 4: Capacitación de los trabajadores de Agua de Hermosillo 2011-2013

\begin{tabular}{|c|c|c|c|c|c|c|c|c|c|c|}
\hline \multirow[b]{2}{*}{ Temática } & \multicolumn{2}{|c|}{2011} & \multicolumn{2}{|c|}{2012} & \multicolumn{2}{|c|}{2013} & \multicolumn{2}{|c|}{$\begin{array}{l}\text { Promedio del } \\
\text { periodo }\end{array}$} & \multicolumn{2}{|c|}{ Total } \\
\hline & Horas & Asist.* & Horas & Asist. & Horas & Asist. & Horas & Asist. & Horas & Asist. \\
\hline $\begin{array}{l}\text { Cómputo y/o } \\
\text { manejo de software }\end{array}$ & 2 & 4 & 0 & 0 & 10 & 40 & 4 & 15 & 12 & 44 \\
\hline $\begin{array}{l}\text { Conocimiento y } \\
\text { manejo de recursos } \\
\text { técnicos }\end{array}$ & 12 & 69 & 12 & 101 & 64 & 1160 & 29 & 443 & 88 & 1330 \\
\hline $\begin{array}{l}\text { Prevención y } \\
\text { seguridad }\end{array}$ & 4 & 10 & 4 & 45 & 22 & 298 & 10 & 118 & 30 & 353 \\
\hline $\begin{array}{l}\text { Superación } \\
\text { personal, inducción } \\
\text { y trabajo en equipo }\end{array}$ & 62 & 392 & 39 & 587 & 32 & 1015 & 44 & 665 & 133 & 1994 \\
\hline $\begin{array}{l}\text { Cuestiones fiscales } \\
\text { y administrativas }\end{array}$ & 0 & 0 & 1 & 35 & 44 & 302 & 15 & 112 & 45 & 337 \\
\hline Otros & 0 & 0 & 0 & 0 & 3 & 677 & 1 & 226 & 3 & 677 \\
\hline Total & 80 & 475 & 56 & 768 & 172 & 2815 & 103 & 1353 & 308 & 4058 \\
\hline
\end{tabular}

Fuente: Elaboración propia con información de la Solicitud de información nro. 00193514 del 30 de abril de 2014 a Agua de Hermosillo vía Infomex. 
De la Tabla 4 resaltan los siguientes aspectos: en el año 2011 se registraron 475 asistencias a los cursos, suponiendo que cada una de esas asistencias representen solo una participación, de los 921 empleados, solamente 52\% recibieron capacitación y el alto número de asistentes que se observa en el periodo (4 058) se debe a que en el año 2013 se realizaron cursos de duración de dos horas pero con asistencia masiva, entre ellos: "Agua en común" al que asistieron 661 empleados, "Mejor ando bien. Mi trabajo" con 451 asistentes, o "Técnicas de las 5 S" con 265 asistentes. La temática "Superación personal, inducción y trabajo en equipo" con un promedio de 1994 asistentes fue la más concurrida al representar $49 \%$ de asistencia; seguida por "Conocimiento y manejo de recursos técnicos" con $33 \%$ de asistencia. Por lo que respecta al tiempo invertido fueron estas dos tématicas a las que se les dedicó la mayor cantidad de horas y en conjunto representaron $82 \%$ de las horas de capacitación. Además, participaron 22 instituciones y dependencias en la impartición de los 91 cursos del periodo, aunque el propio ooA impartió $72 \%$ del total.

Finalmente el tiempo programado para capacitación en los tres años fue de 308 horas, por lo tanto, la tarea para el organismo es replantear su programa de capacitación, buscar incrementar el número de horas, mejorar el diagnóstico de necesidades de capacitación, hacer extensiva la capacitación a todos sus trabajadores, pero sobre todo, cumplir con el programa.

\section{Capacitación y desarrollo en la Comisión Estatal de Servicios Públicos de Mexicali}

El contrato colectivo de la CESPM establece que el organismo "adiestrará y/o capacitará a los trabajadores para que desempeñen con eficiencia sus labores y los preparará para obtener ascensos conforme al Reglamento de Escalafón" (Contrato Colectivo de Trabajo 2012-2013, 2012, p. 10). La Subdirección Administrativa es el área encargada de cumplir con este compromiso ${ }^{21}$ a través del Departamento de Recursos Humanos (Reglamento Interno de la Comisión Estatal de Servicios Públicos de Mexicali, 2007). Sin embargo, la preparación del empleado no es el único camino para ascender dentro del organismo, ya que de acuerdo al CCT de la CESPM "se obliga a promover automáticamente al nivel inmediato superior al trabajador sindicalizado que haya permanecido estático en un nivel comprendido del $01^{\mathrm{a}}$ al 10 por el término de dos años" (Contrato Colectivo de Trabajo 2012-2013, 2012, p. 20).

Al igual que en Hermosillo, la DNC es el método implementado por la Subdirección Administrativa del ooA de Mexicali para diseñar sus programas de capacitación. La Tabla 5 refleja que dan un buen seguimiento al programa de capacitación ya que practicamente todas las acciones programadas en los POA en el periodo se logró ejecutar con un (más o menos) 20\% de las acciones. Por otra parte, la información ${ }^{22}$ que presentaron como respuesta, se clasificó en cinco grandes temáticas.

\footnotetext{
${ }^{21}$ De acuerdo al manual de organización de CESPM, entre las tareas encomendadas a la Subdirección Administrativa se encuentra: "Coordinar la capacitación, adiestramiento y fomentar el desarrollo de personal" (Manual de Organización General, 2013, p. 22).

22 Solicitud de información UCT-141017 del 30 de abril de 2014 a la Comisión Estatal de Servicios Públicos de Mexicali, vía Infomex.
} 
Tabla 5: Actividades de capacitación implementadas por la Comisión Estatal de Servicios Públicos de Mexicali 2008-2013

\begin{tabular}{|c|c|c|c|c|c|c|}
\hline \multicolumn{4}{|c|}{ Programa Operativo Anual 2008-2013 } & \multicolumn{3}{|c|}{ Metas anuales } \\
\hline Año & Descripción & $\begin{array}{l}\text { Unidad } \\
\text { responsable }\end{array}$ & $\begin{array}{l}\text { Unidad de } \\
\text { medida }\end{array}$ & Programado & Ejecutado & $\begin{array}{l}\% \text { de } \\
\text { cumpli- } \\
\text { miento }\end{array}$ \\
\hline 2013 & $\begin{array}{l}\text { Acciones para coadyuvar } \\
\text { al fortalecimiento } \\
\text { institucional }\end{array}$ & $\begin{array}{l}\text { Subdirección } \\
\text { Administrativa }\end{array}$ & Curso & 43 & $\mathrm{~s} / \mathrm{d}$ & 0 \\
\hline 2012 & $\begin{array}{l}\text { Acciones para coadyuvar } \\
\text { al fortalecimiento } \\
\text { institucional }\end{array}$ & $\begin{array}{l}\text { Subdirección } \\
\text { Administrativa }\end{array}$ & Personas & 777 & 903 & 116 \\
\hline 2011 & $\begin{array}{l}\text { Acciones para coadyuvar } \\
\text { al fortalecimiento } \\
\text { institucional }\end{array}$ & $\begin{array}{l}\text { Subdirección } \\
\text { Administrativa }\end{array}$ & Personas & 662 & 662 & 100 \\
\hline 2011 & $\begin{array}{c}\text { Formalización de las } \\
\text { notificaciones de los actos } \\
\text { administrativos }\end{array}$ & Planeación & Cursos & 12 & 12 & 100 \\
\hline 2010 & $\begin{array}{l}\text { Incrementar la calidad } \\
\text { en la atención }\end{array}$ & $\begin{array}{l}\text { Subdirección } \\
\text { Administrativa }\end{array}$ & Personas & 721 & 721 & 100 \\
\hline 2009 & $\begin{array}{c}\text { Capacitar al } 89 \% \text { de la } \\
\text { plantilla del personal }\end{array}$ & $\begin{array}{l}\text { Subdirección } \\
\text { Administrativa }\end{array}$ & Personas & 1128 & 1175 & 104 \\
\hline $2008 *$ & $\begin{array}{c}\text { Capacitar al personal del } \\
\text { organismo }\end{array}$ & $\begin{array}{l}\text { Subdirección } \\
\text { Administrativa }\end{array}$ & Personas & 3276 & 4055 & 124 \\
\hline
\end{tabular}

2008*: En este año el número de empleados programados y capacitados se incrementó considerablemente debido a los movimientos sísmicos presentados en febrero de ese año y otros cursos que eran de interés de todo el personal que labora en la CESPM como el curso: Integración de equipos para el personal de CESPM, y El valor del Trabajo.

Fuente: Elaboración propia con información del Portal de TransparenciaBc. ${ }^{23}$

De acuerdo con la Tabla 6, en 2013 de las 1271 personas que laboraban en la CESPM $^{24}$ solamente $53 \%$ recibió capacitación (suponiendo que cada uno de los asistentes registrados tomó solamente un curso de capacitación), pero a diferencia de Hermosillo, se destinaron a la capacitación 1964 horas. En el periodo 2011-2013 la temática "Conocimiento y manejo de recursos técnicos" con 995 asistencias fue la más concurrida al representar $41 \%$ del total; seguida por "Prevensión y seguridad" con $19 \%$ en asistencia. Por lo que respecta al tiempo invertido, a la temática "Conocimiento y manejo de recursos técnicos" se le destinó 38\% del total del tiempo de capacitación. Asimismo, en la impartición de los 147 cursos participaron 64 expositores (11 personas físicas y 54 morales), de las cuales la CESPM impartió $28 \%$ del total, seguida por la Comisión Estatal del Agua (CEA) de Baja California con 7\%. ${ }^{25}$

23 Sin embargo, en el enlace http://dceg.bajacalifornia.gob.mx/Sasip/frmPublicacionesDeOficio.aspx?id=1045 actualmente solo se encuentran disponibles los años 2015, 2016 y 2017.

${ }^{24}$ Solicitud de información UCT-141017 del 30 de abril de 2014 a la Comisión Estatal de Servicios Públicos de Mexicali, vía Infomex.

${ }^{25}$ Entre las que destaca: la CEA B.C., UABC, COPARMEX, Conagua, Banco de Desarrollo de América del Norte, IMTA, CFE, Instituto para el Desarrollo Técnico (INDETEC), entre otros. 
Tabla 6: Capacitación de los trabajadores de la Comisión Estatal de Servicios Públicos de Mexicali 2011-2013

\begin{tabular}{|c|c|c|c|c|c|c|c|c|c|c|}
\hline & \multicolumn{2}{|c|}{2011} & \multicolumn{2}{c|}{2012} & \multicolumn{2}{c|}{2013} & \multicolumn{2}{c|}{$\begin{array}{c}\text { Promedio del } \\
\text { periodo }\end{array}$} & \multicolumn{3}{c|}{ Total } \\
\hline Temática & Horas & Asist. & Horas & Asist. & Horas & Asist. & Horas & Asist. & Horas & Asist. \\
\hline $\begin{array}{c}\text { Cómputo y/o } \\
\text { manejo de } \\
\text { software }\end{array}$ & 156 & 125 & 8 & 19 & 60.5 & 118 & 75 & 87 & 224.5 & 262 \\
\hline $\begin{array}{c}\text { Conocimiento } \\
\text { y manejo } \\
\text { de recursos } \\
\text { técnicos }\end{array}$ & 129 & 181 & 478 & 583 & 138.5 & 191 & 249 & 318 & 745.5 & 955 \\
\hline $\begin{array}{c}\text { Prevención y } \\
\text { seguridad }\end{array}$ & 49 & 140 & 126 & 153 & 53.5 & 143 & 76 & 145 & 228.5 & 436 \\
\hline $\begin{array}{c}\text { Superación } \\
\text { personal, } \\
\text { inducción y } \\
\text { trabajo en } \\
\text { equipo }\end{array}$ & 60 & 60 & 6 & 84 & 50 & 172 & 39 & 105 & 116 & 316 \\
\hline $\begin{array}{c}\text { Cuestiones } \\
\text { fiscales y } \\
\text { administrativas }\end{array}$ & 303 & 172 & 192 & 43 & 41 & 53 & 179 & 89 & 536 & 268 \\
\hline Otros & 108 & 63 & 6 & 4 & 0 & 0 & 38 & 22 & 114 & 67 \\
\hline \begin{tabular}{c} 
Total \\
\hline
\end{tabular} & 805 & 741 & 816 & 886 & 343.5 & 677 & 654.8 & 768 & 1964.5 & 2304 \\
\hline
\end{tabular}

Fuente: Elaboración propia con datos de la Solicitud de información ucT-141017 del 30 de abril de 2014 a la Comisión Estatal de Servicios Públicos de Mexicali vía Infomex.

Este apartado permite observar que Agua de Hermosillo posee un marco legal que permite a la dirección del organismo tener un mejor control respecto a las políticas de promoción, ya que concede facilidades para promover al personal a la vez de exigirles capacidad para desarrollar nuevas funciones. Sin embargo, el organismo presenta dificultades para cumplir con su programa de capacitación, además de que los cursos que ofrece son limitados y en algunos casos no exceden las dos horas de duración y se imparte de manera indiferenciada a cientos de trabajadores. Los programas de capacitación de la CESPM cubren una amplia variedad de temas que permiten a sus empleados poder elegir según sus necesidades de aprendizaje, sin embargo, el sistema de escalafón permite el ascenso en automático de acuerdo al criterio de antigüedad.

\section{Salarios, prestaciones y estímulos}

El costo total respecto a la remuneración que percibe un empleado de confianza en Hermosillo es de aproximadamente 228500 pesos anuales (19 041.67 mensuales ). De los empleados, 213 son de confianza y 708 sindicalizados, quienes representan para el organismo, un costo anual (incluye salario, y el sistema de estímulos y 
compensaciones) de aproximadamente $72278^{26}$ pesos anuales por cada uno de ellos. Es decir, un empleado de confianza percibe mensualmente un ingreso promedio de aproximadamente de $316 \%$ más que uno sindicalizado. Considerando empleados de confianza y sindicalizados, la remuneración total anual promedio que percibió un empleado para Agua de Hermosillo en el año 2012 fue de aproximadamente 108407 pesos (9 033 pesos mensuales).

Asimismo, en el Reporte de Saldos Globales por Objeto del Gasto $2012^{27}$ el organismo destinó para la partida Servicios personales 230457694 pesos. De estos recursos, $32 \%$ se destinó al pago de sueldos de $921^{28}$ trabajadores, lo que representó un costo anual promedio de 79946 pesos por empleado (ver Tabla 7).

Tabla 7: Gasto en servicios personales en Agua de Hermosillo y la Comisión Estatal de Servicios Públicos Mexicali del año 2012

\begin{tabular}{|l|c|c|}
\hline \multicolumn{1}{|c|}{ Concepto } & Agua de Hermosillo & CESPM \\
\hline Número de empleados & 921 & 566 \\
\hline Número de empleados sindicalizados & 708 & 705 \\
\hline Número de empleados de confianza & 213 & 1271 \\
\hline Servicios personales & 230457694 & 150697038 \\
\hline Pago de sueldos & 73630417 & 125628 \\
\hline Ingreso promedio anual por empleado & 79946 & 112896 \\
\hline $\begin{array}{l}\text { Ingreso promedio anual por empleado } \\
\text { base }\end{array}$ & $72278^{* *}$ & 443154 \\
\hline $\begin{array}{l}\text { Ingreso promedio anual por empleado de } \\
\text { confianza }\end{array}$ & $228500^{* *}$ & 352060 \\
\hline Costo anual del personal sindicalizado & $\mathrm{n} / \mathrm{d}$ & 399566 \\
\hline Costo anual del personal de confianza & $\mathrm{n} / \mathrm{d}$ & 250226 \\
\hline Costo anual del personal & & \\
\hline
\end{tabular}

*Incluye la suma de 8820496 del personal clasificado en otros.

**Estimación con base en tabulador consultado en el portal electrónico de Agua de Hermosillo.

Fuente: Solicitud de información nro. 76014 del 26 de febrero de 2014 a Agua de Hermosillo vía Infomex y CESPM. ${ }^{29}$

\footnotetext{
${ }^{26}$ Cálculo realizado con información del portal electrónico de Agua de Hermosillo.

${ }^{27}$ Solicitud de información nro. 76014 del 26 de febrero de 2014 a Agua de Hermosillo vía Infomex.

${ }^{28}$ No se pudo desglosar la información por tipo de contratación ya que la información obtenida a través de la Solicitud de información folio 182014 de abril de 2014 dirigida a Agua de Hermosillo resultó incompleta y confusa para el análisis.

29 Para su consulta en línea http://cim.ebajacalifornia.gob.mx/CIM/Publicacion/Temporal/2014_4_7_8_2_3_14.pdf pero el año más reciente que aparece es el 2014.
} 
En el caso de Mexicali, en el CCT CESPM (Contrato Colectivo de Trabajo 2012-2013, 2012) se establecen los salarios que perciben cada uno de los empleados de acuerdo con su puesto. En el año 2012 se destinaron 150697038 pesos solo para cubrir el salario de 1271 empleados, lo que generó un costo promedio anual de 118565 pesos por empleado. Este pagó representó $29.7 \%$ del total del costo de la partida de Servicios personales. Respecto al costo por tipo de contratación, el gasto anual promedio por cada empleado sindicalizado fue de 125628 pesos (9 408 mensuales), mientras que para los de confianza fue de 112896 (10 469 mensuales). En términos comparativos, en lo referente al pago de salarios, los empleados de Mexicali perciben aproximadamente $32 \%$ más que los de Hermosillo.

\section{Estímulos y prestaciones}

En Hermosillo, en el cCT se establecen las prestaciones laborales que sirven para complementar el ingreso de los trabajadores que suman un gasto total de 126271728 de pesos que es $42 \%$ superior al pago de salarios (Contrato Colectivo de Trabajo 2012, 2012).

En Mexicali, de acuerdo al CCT el ingreso de los trabajadores se complementan con las "Remuneraciones adicionales y especiales" y "Otras prestaciones sociales y económicas" que representan un monto de 294300 147, es decir, 49\% superior al destinado para el pago de salarios (Contrato Colectivo de Trabajo 2012-2013, 2012).

\section{Gasto en seguridad social}

Los OOA también destinan recursos económicos para cubrir los servicios de salud de sus trabajadores, así como asegurar una fuente de ingresos después de su retiro de la vida laboral. Entre las principales se encuentran: cuotas por servicio médico, otras prestaciones de seguridad social; pagos de defunción, pensiones y jubilaciones, aportaciones al fondo de ahorro de los trabajadores; indemnizaciones al personal, seguros colectivos; entre otros. En el año 2012 en Hermosillo se destinó a este rubro $12.6 \%$ del total de los pagos a Servicios Personales. ${ }^{30}$

Por otra parte, en Mexicali el gasto destinado a cubrir las aportaciones de Seguridad social representó aproximadamente 12\% (61 274 993) de la categoría de Servicios personales. También en los СCT de los organismos encontramos otras prestaciones que resultan en beneficio de los trabajadores que son superiores a las señaladas en la Ley Federal del Trabajo (1970) respecto a la jornada de trabajo y al periodo vacacional. Estos beneficios si bien no repercuten directamente en el salario, pueden significar un alto costo para los organismos si no programan adecuadamente las tareas a ejecutar.

Además, algunos de los beneficios que otorgan los organismos a sus trabajadores lo reciben a través del sindicato, en la Tabla 8 se presenta un resumen de la información que otorgaron los organismos respecto al pago que hicieron a los sindicatos. Es importante señalar que no todo el monto se destina a los trabajadores ya que los sindicatos utilizan un porcentaje para sufragar sus propios gastos.

${ }^{30}$ Solicitud de información nro. 76014 del 26 de febrero de 2014 a Agua de Hermosillo vía Infomex. 
Tabla 8: Pagos de los organismos de agua a los sindicatos en el periodo 2008-2012

\begin{tabular}{|c|c|c|}
\hline Año & Agua de Hermosillo & CESPM \\
\hline 2008 & 1389896 & 5774678 \\
\hline 2009 & 732513 & 6513240 \\
\hline 2010 & 1337682 & 6035626 \\
\hline 2011 & 2714603 & 5845835 \\
\hline 2012 & 3433014 & 5569288 \\
\hline Total & 9607707 & 29738667 \\
\hline
\end{tabular}

Fuente: Elaboración propia a través de la Solicitud de información nro. 282514 del 26 de febrero de 2014 a Agua de Hermosillo vía Infomex y de la Solicitud de Información nro. 141330 el 26 de junio de 2014 a CESPM vía Infomex.

Mientras que el costo promedio anual por empleado fue de \$142 003 en Agua de Hermosillo, en la CESPM fue de $\$ 226966^{31}$ pesos. El costo promedio total de Servicios personales para Agua de Hermosillo por empleado fue de \$250 225 pesos aproximadamente, mientras que para cada empleado de la CESPM fue de alrededor de \$399000 pesos. Esta diferencia parece fundamentar la preocupación del titular de la CESPM, ya que el costo que representa para el organismo es aproximadamente 62\% mayor al costo por empleado que representa para Agua de Hermosillo. Pero también deben de analizar los beneficios que generan ${ }^{32}$ el contar con ingresos por encima del ingreso corriente total per cápita (ICTPC) de Hermosillo y Mexicali, y que se manifiestan en la casi nula rotación del personal de base y en el desempeño de sus funciones. ${ }^{33}$ Sin embargo, es conveniente notar que los gastos en servicios personales constituyen una proporción considerable de los gastos de ambos organismos: en 2012, Agua de Hermosillo utilizó $36 \%$ de su presupuesto de egresos para el pago de este rubro, mientras que la CESPM destinó $44 \% .^{34}$

\section{Sanciones}

Tanto en el Contrato Colectivo de Trabajo 2012 (2012) como en el Reglamento Interior de Agua de Hermosillo (2013) tienen apartados para especificar las causas de sanción para

${ }^{31}$ Incluye salario tabular, salario interinos, servicios sociales a estudiantes y profesionistas, primas por años de servicios efectivos, prima de antigüedad, prima dominical, prima vacacional, aguinaldos, tiempo extraordinario y compensación.

${ }^{32}$ El dirigente municipal del PRI en Mexicali, un periodista que cubre las notas de la CESPM, y un representante de la Canaco ante el Consejo de Administración del organismo, coincidieron en señalar que el organismo realiza un trabajo aceptable.

${ }^{33}$ Un funcionario de la CESPM mencionó que para muchas personas de la ciudad de Mexicali representa una motivación ingresar a trabajar en la CESPM por el clima laboral que prevalece, por lo que una vez que ingresan, tratan de realizar su mejor esfuerzo para mantenerse dentro de la paraestatal.

${ }^{34}$ Para el caso de Hermosillo: Solicitud de información nro. 76014 del 26 de febrero de 2014 vía Infomex; para el caso de Mexicali: CESPM, desde el portal de TransparenciaBC. 
los trabajadores, que pueden ser desde una amonestación y suspensión temporal, hasta faltas graves que pueden provocar la rescisión del contrato individual de trabajo. En este sentido, se establece que en caso de que un trabajador cometa faltas que son sancionables, el organismo emitirá las sanciones correspondientes con el apoyo del sindicato. También se estipula que en caso de que el sindicato sancione al trabajador con suspensiones, el organismo apoyará estas decisiones. El Reglamento, en el capítulo xiv indica 29 prohibiciones. Además de que el artículo 52 señala el abandono de trabajo como una de las causas para terminar la relación laboral. Del mismo modo, el capítulo Xvi especifica las causas que pueden dar paso a una rescisión laboral.

En el caso de la Comisión Estatal de Servicios Públicos de Mexicali, el Contrato Colectivo de Trabajo 2012-2013 (2012) no especifica las sanciones o posibles causas que pueden generar la rescisión del trabajador. Sin embargo, el capítulo ir de la Ley del Servicio Civil de los Trabajadores al Servicio de los Poderes del Estado, Municipios e Instituciones Descentralizadas de Baja California (1989) establece las causas que dan origen a la terminación laboral siempre y cuando sea por una razón justificada. Al igual que las razones emitidas en el marco legal de Agua de Hermosillo van desde las más lógicas como el fallecimiento del trabajador o terminación del contrato, hasta actos deshonestos o inmorales, abandono de trabajo, faltas injustificadas, entre otros.

\section{Diferencias y similitudes de los Sistemas de Gestión de Recursos Humanos de Agua de Hermosillo y la Comisión Estatal de Servicios Públicos de Mexicali}

A pesar de que ambos organismos presentan deficiencias en sus SGRH, encontramos diferencias en dos de las cuatro categorías esbozadas en la introducción para desarrollar en el análisis: 1) Políticas de contratación de personal, 2) Desarrollo y capacitación, 3) Salario, prestaciones y estímulos, y el 4) Sistema de sanciones. Las políticas de selección y contratación de la CESPM y Agua de Hermosillo están diseñadas para mantener el control del sindicato en el personal permanente y del titular del poder ejecutivo sobre el personal de confianza. Este control se refuerza con las políticas tanto en los beneficios o apoyos que se entregan a través de los sindicatos, como las establecidas en el Sistema de sanciones, ya que para poder amonestar o sancionar a un empleado se requiere del apoyo mutuo organismo-sindicato.

En donde se encuentran diferencias que pueden explicar parte del desempeño diferenciado de los dos organismos, son en los incisos 2 y 3 . Respecto al inciso 2. Desarrollo y capacitación del personal, en el caso de Agua de Hermosillo, se carece de elementos que permitan realmente vincular el conocimiento al desarrollo ya que sus programas de capacitación son escasos y de corta duración. Por otra parte, no hay seguimiento al programa de capacitación: Agua de Hermosillo no tiene un registro del personal que asiste a cursos externos, para el curso "Capacitación del personal" que atiende al usuario se programaron 40 personas y no se capacitó a ninguna. Formalmente, Agua de Hermosillo pretende vincular la capacitación con el desarrollo, pero no programa los cursos que requieren los empleados, ni planifica las cargas de trabajo para que puedan asistir. 
En cambio la CESPM, a pesar de que tiene vinculados los ascensos al criterio de la antigüedad, tiene un mejor control sobre sus programas de capacitación, son variados y se destina una mayor cantidad de horas que en Agua de Hermosillo. Esto ha influido para que el número de quejas recibidas sea considerablemente menor que el de Agua de Hermosillo. Respecto al inciso 3. Salario, prestaciones y estímulos, los sueldos y prestaciones de los empleados de la CESPM son muy superiores a los de Agua de Hermosillo, lo que constituye un aliciente para conservar su puesto en la paraestatal, considerando que el ICTPC mensual del municipio de Hermosillo en 2010 fue de \$4 120 pesos, mientras que el de Mexicali fue de \$3 611 (Consejo Nacional de Evaluación de la Política de Desarrollo Social [Coneval], 2010).

\section{Conclusiones}

El desempeño de los organismos de agua se ve afectado por distintos factores, algunos de carácter natural como el clima, precipitación pluvial, cuencas, afluencia de ríos, etcétera, otros donde interviene la mano del hombre, principalmente a través de la gestión de recursos humanos, materiales, financieros y tecnológicos. Los factores vinculados a la gestión son indudablemente más importantes, pues no es una garantía que aquellos lugares donde se dispone de gran abundancia de agua, el servicio que prestan los organismos de agua sea de calidad, continuo y eficiente. ${ }^{35}$ Es aquí, donde el recurso humano se traduce en un elemento fundamental para dotar de un servicio de calidad a las poblaciones sin importar las condiciones sociodemográficas de los lugares que habitan. Es por ello que los SGRH son un tema de interés para entender la gestión de las organizaciones.

Los SGRH tanto de Agua de Hermosillo como de la CESPM, presentan características patrimonialistas y una excesiva intervención de sindicatos (personal de base) que obstaculizan el establecimiento de un sistema de servicio civil de carrera. Además, estas prácticas se encuentran formalmente institucionalizadas ya que están incorporadas en el marco jurídico, por lo que las políticas que rigen los SGRH de los dos organismos son limitados por el marco normativo, y por la injerencia de actores con intereses ajenos a los organismos. A pesar de esta situación, tanto Agua de Hermosillo como la CESPM, muestran desempeños diferenciados, y en las categorías estudiadas se observan diferencias que explican en parte las observaciones anteriormente presentadas.

Respecto a la primera categoría, Políticas de contratación de personal, los dos organismos son públicos por ello la designación del personal directivo es facultad directa o indirecta de los titulares del poder ejecutivo del nivel de gobierno correspondiente, y donde la selección no siempre o casi nunca ha sido la más acertada. Como ejemplo de ello, el director en Agua de Hermosillo durante el periodo 20122015 no cumplía con el perfil, mientras que más de un funcionario del organismo de agua de Mexicali se excusó de proporcionar una entrevista debido a que tenían poco

\footnotetext{
${ }^{35}$ Por ejemplo, Acapulco, Villahermosa y Tuxtla Gutiérrez tienen calificaciones más bajas por parte de los usuarios que la mayoría de los municipios evaluados en la ENCIG. Un análisis de Salazar y Lutz (2015) señala que en México los oOA ubicados en zonas de mayor precipitación pluvial tienen menores niveles de desempeño.
} 
tiempo en su puesto y desconocían sus funciones y problemáticas de la paraestatal. En lo referente al personal de base, los dos organismos se encuentran adheridos en sindicatos, los cuales son los responsables de negociar las prestaciones laborales y en sus CCT se observan muchas similitudes. Estos factores, de acuerdo con Kneedler et al. (2000) generan un sistema de gestión poco eficiente.

En la segunda categoría, Desarrollo y capacitación, en la CESPM se observa que realizan una mejor planificación y un mejor uso de sus recursos materiales y humanos, a pesar de tener una planta laboral (en promedio por cada 1000 habitantes) muy similar a la de Agua de Hermosillo, el personal de la CESPM logra cubrir todas las rutas de micromedición, los cursos de capacitación aparentemente están diseñados para fortalecer las necesidades del personal, en promedio general, otorga un mayor número de horas de capacitación que el de Agua de Hermosillo, en donde la capacitación que se proporciona a los trabajadores es dispersa y sin definir un objetivo en concreto, por ello no es casualidad que no cumplan con sus programas de capacitación, además de no llevar un control de la capacitación externa que reciben sus trabajadores. En resumen, en Agua de Hermosillo se imparten menos horas de capacitación, no se cumple con los objetivos y se desatienden áreas importantes como sistemas y atención a usuarios, los cuales debieran ser prioritarios en un ooA que busca mejorar sus indicadores de recaudación, medición y pérdidas de agua.

Respecto a la tercera categoría Salario, prestaciones y estímulos, en un organismo como la CESPM, un salario muy por encima ICTPC de la ciudad constituye un incentivo para realizar su mejor esfuerzo para permanecer dentro de la organización. Y si bien los OOA requieren de incentivos para que su personal trabaje en beneficio del mejoramiento del servicio de agua potable, también se requieren sanciones para disuadir al personal de acciones que perjudiquen al ooA. En este sentido, los Sistemas de sanciones de los dos organismos presentan deficiencias, ambos se caracterizan por la necesidad del apoyo del sindicato para poder sancionar a sus trabajadores. Finalmente, el desempeño de los ooA de Hermosillo y Mexicali es producto de su diseño institucional y la constante interacción de factores políticos, administrativos y humanos (Loera, 2015), por lo que es difícil determinar el peso que cada factor puede tener sobre el desempeño general. Sin embargo, los dos casos analizados indican que el ooA con mejor desempeño cuenta con un mejor sistema de capacitación e incentivos. Sería recomendable que investigaciones futuras sobre los SGRH en el sector agua potable, incluyan una muestra más grande que permita ver de manera más clara el impacto de estos sistemas sobre el desempeño. La experiencia internacional señala que el desarrollo del factor humano, es clave para generar organismos eficientes, por ello es necesario que en los OOA (y en general en la administración pública) se logre diseñar el andamiaje jurídico para limitar la discrecionalidad del poder ejecutivo en la designación del personal directivo, a la vez de fortalecer el proceso de contratación de personal operativo conforme a la competencia de los candidatos, así como, diseñar mecanismos de desarrollo basado en las aptitudes de los trabajadores.

\section{Referencias}

Aboites, L., Birrichaga, D. y Garay, J. A. (2010). El manejo de las aguas mexicanas en el siglo xx. En B. Jiménez, M. L. Torregrosa y L. Aboites (Coords.), El agua en México. Cauces y encauces (pp. 21-49). México: Academia Mexicana de Ciencias, Conagua. 
Agua de Hermosillo. (s.f.). Recuperado de http://www.aguadehermosillo.gob.mx/ inicio/index.php/organismo/aguah-en-numeros

Biswas, A. y Tortajada, C. (2009). Water supply of phnom penh: A most remarkable transformation. Recuperado del sitio de Internet de Third World Centre for Water Management http://www.thirdworldcentre.org/wpcontent/uploads/2015/04/ phnompenhrep.pdf

Brinkerhoff, D. W. y Goldsmith, A. A. (2002). Clientelism, patrimonialism and democratic governance: an overview and framework for assessment and programming. Cambridge, Estados Unidos: U.S. Agency for International Development, Office of Democracy and Governance, Abt Associates Inc.

Camacho, J. I. (2014). La Flexibilidad laboral y la negociación colectiva. En P. Kurczyn y R. Tena (Coords.), Temas Selectos de Derecho Laboral (pp. 1-38). México: Universidad Nacional Autónoma de México.

Chiavenato, I. (2007). Administración de recursos humanos. El capital humano de las organizaciones. México: McGraw-Hill.

Comisión Estatal de Servicios Públicos del municipio de Mexicali (CESPM). (s.f.). Recuperado de http://dceg.bajacalifornia.gob.mx/Sasip/frmPublicacionesDeOficio.aspx?id=1045

Comisión Nacional del Agua (Conagua). (s.f.). Objetivos y estrategias. Recuperado de http://www.gob.mx/cms/uploads/attachment/file/109732/OBJETIVOS_Y_ ESTRAT_GIAS.pdf

Comisión Nacional del Agua (Conagua). (2013). Situación del subsector agua potable, alcantarillado y saneamiento. México: Semarnat, Conagua.

Consejo Nacional de Evaluación de la Política de Desarrollo Social (Coneval). (2010). Medición de la pobreza. Recuperado de http://www.coneval.gob.mx/Medicion/ Paginas/Medici\%C3\%B3n/Medicion-de-la-pobreza-municipal-2010.aspx

Consejo Nacional de Población (CONAPO). (2015). Datos abiertos del índice de marginación. Recuperado de http://www.conapo.gob.mx/es/CONAPO/Datos_Abiertos_del_Indice_de_Marginacion

Garza, E. de la (2003). Sindicatos, flexibilidad y productividad. Recuperado de http:// sgpwe.izt.uam.mx/pages/egt/congresos/sindprodflex.pdf

Grindle, M. (1977). Patrons and clients in the bureaucracy: Career networks in Mexico. Latin American Research Review, 12(1), 37-66.

Instituto de Transparencia Informativa del Estado de Sonora (Ities). (2017). VIII. Las metas y objetivos de las unidades administrativas, de conformidad con sus programas operativos. Recuperado de http://transparenciasonora.org.mx/leydesecciones. php?art=8\&id $=12$

Instituto Nacional de Estadística y Geografía (Inegi). (2015). Encuesta Nacional de Calidad e Impacto Gubernamental (ENCIG). Recuperado de http:/ / www.beta.inegi.org. $\mathrm{mx} /$ proyectos/enchogares/regulares/encig/2015/default.html

Kneedler, D. A., Selden, S. C. e Ingraham, P. (2000). Measuring government management capacity: A comparative analysis of city human resources management systems. Journal of Public Administration Research and Theory, 10(2), 381-411.

Loera, E. (2015). Capacidad institucional y desempeño en los organismos públicos de agua. Un estudio comparativo de Agua de Hermosillo y la Comisión Estatal de Servicios Públi- 
cos de Mexicali (2003-2012) (Tesis doctoral). El Colegio de Sonora, Hermosillo, Sonora, México.

Longo, F. (2004). La calidad de los sistemas de servicio civil en América Latina y el Caribe: una metodología de evaluación. Revista del CLAD Reforma y Democracia, 28, 1-17.

Lusthaus, C., Adrien, M. H., Anderson, G., Carden, F. y Plinio, G. (2002). Evaluación organizacional: marco para mejorar el desempeño. Estados Unidos de América: Banco Interamericano de Desarrollo.

Lutz, A. N. y Salazar, A. (2012). Evolución y perfiles de eficiencia de los organismos operadores de agua en México. Estudios Demográficos y Urbanos, 26(3), 563-599.

Mansilla, H. C. F. (1991). Neopatrimonialismo, élite de poder y expansión de la burocracia. Politica y Sociedad, 8, 113-124.

Meyer-Sahling, J. H. (2004). Civil Service reform in Post-Communist Europe: The Bumpy Road to Depoliticisacion. West European Politics, 27(1), 71-103.

Moon, M. J. y Hwang, C. (2013). The state of civil service systems in the Asia-Pacific region: A comparative perspective. Review of Public Personnel Administration, xx(x), 1-19.

Moreno, J. L. (2015). Despojo de agua en la cuenca del río Yaqui. México: El Colegio de Sonora.

Oszlak, O. (1980). Políticas públicas y regímenes políticos: Reflexiones a partir de algunas experiencias latinoamericanas. Estudios CEDES, 3(2), 1-38.

Oszlak, O. (2002). Sistemas de servicio civil en América Latina y el Caribe: situación actual y desafíos pendientes. Revista de Servicio Civil, (13), 1-7.

Pineda, N. y Briseño, H. (2012). ¿Por qué son mejores los organismos de agua de Baja California que los de Sonora? Instituciones locales y desempeño de los organismos públicos. Región y Sociedad, (Núm. Especial 3), 181-212.

Programa de Indicadores de Gestión de Organismos Operadores (PIGOo). (s.f.). Tabla de indicadores. Recuperado de http://www.pigoo.gob.mx/dashboard/exportar/ pdf/exportar_consulta_pdf.php?tipo=cd\&id $=42$

Programas de Indicadores de Gestión de Organismos Operadores (PIGOO), Instituto Mexicano de Tecnología del Agua (IMTA), Secretaría de Medio Ambiente y Recursos Naturales (Semarnat). (s.f.). Promedio de cobertura de agua potable reportada. Recuperado de http://www.pigoo.gob.mx/index.php?option=com_content\&view $=$ article \&id $=35 \&$ Itemid $=525 \% 2015$

Roth, G. (1968). Personal rulership, patrimonialism, and empire-building in the new states. World Politics, 20(2), 194-206.

Salazar, A. y Lutz, A. (2015). Factores asociados al desempeño en organismos operadores de agua potable en México. Región y Sociedad. Revista de El Colegio de Sono$r a, 27(62), 5-26$.

Tortajada, C. (2006). Water management in Singapore. Water Resources Development, 22(2), 227-240. 


\section{Material legislativo}

Carta Iberoamericana de la Función Pública [Centro Latinoamericano de Administración para el Desarrollo, Naciones Unidas Departamento de Asuntos Económicos y Sociales]. 2003. Recuperado de http://old.clad.org/documentos/declaraciones/cartaibero.pdf/view

Contrato Colectivo de Trabajo 2012 [Agua de Hermosillo, Sindicato de Trabajadores de Agua de Hermosillo-Confederación de Trabajadores de México]. 22 de marzo de 2012.

Contrato Colectivo de Trabajo 2012-2013 [Comisión Estatal de Servicios Públicos de Mexicali, Sindicato Único de Trabajadores al Servicios de los Poderes del Estado, Municipios e Instituciones Descentralizadas de Baja California, Sección Mexicali]. 1 de mayo de 2012.

Decreto del Ejecutivo del Estado mediante el cual se condona a los usuarios del servicio doméstico, el 100\% del pago de las contribuciones omitidas por concepto de derechos por consumo de agua, así como sus recargos y multas que se hayan generado hasta el 31 de diciembre de 2012. 4 de febrero de 2014. Periódico Oficial del Estado de Baja California tomo cxxi, No. 6, Número Especial.

Instructivo para la Formulación de los Programas Operativos Anuales 2015 [Morelos Poder Ejecutivo, Secretaría de Hacienda]. (2014). Recuperado de http://evaluacion.ssm.gob.mx/pdf/Poa/InstructivoPOA2015-Junio2014.pdf

Ley del Servicio Civil de los Trabajadores al Servicio de los Poderes del Estado, Municipios e Instituciones Descentralizadas de Baja California. 20 de octubre de 1989. Periódico Oficial No. 29, sección I, tomo xcvi.

Ley Federal del Trabajo. Art. 9. 1 de abril de 1970. Diario Oficial de la Federación.

Ley Federal del Trabajo. Art. 154. 1 de abril de 1970. Diario Oficial de la Federación.

Manual de organización de Agua de Hermosillo [Agua de Hermosillo]. 2011.

Manual de Organización General [Comisión Estatal de Servicios Públicos de Mexicali]. Marzo de 2013. Recuperado de http://www.cespm.gob.mx/publicacionesdescripcion.php?clavePublicaciones $=880$

Programa Operativo Anual [POA], 2013. Recuperado de http://www.hermosillo. gob.mx/download.aspx?r=/transparencia2014 \archivos $\backslash$ agua|\&file=POA 2013 (NUEVO FORMATO).pdf

Reglamento Interior de Agua de Hermosillo. 18 de julio de 2013. Boletín Oficial de Sonora No. 6, sección I, tomo cXciI (6).

Reglamento Interno de la Comision Estatal de Servicios Publicos de Mexicali [Comisión Estatal de Servicios Publicos de Mexicali]. 5 de enero de 2007. 
Edmundo Loera Burnes

Mexicano. Doctor en Ciencias Sociales en el Área de asuntos Públicos por el Colegio de Sonora. Director de Área en la Coordinación Ejecutiva de la Oficina del Ejecutivo estatal, Gobierno del Estado de Sonora. Publicación más reciente: Loera, Edmundo, Alejandro Salazar y Noemi Haro. (2016). "Mucha agua, poco pago: el desempeño de la Comisión Estatal de Servicios Públicos de Mexicali”. En A. Salazar (Coordinador): Fugas de agua y dinero. Factores político-institucionales que inciden en el desempeño de los organismos operadores de agua en México (pp. 123-157). Línea de investigación: capacidad de gestión en la prestación de servicios públicos.

Alejandro Salazar Adams

Mexicano. Doctor en Problemas Económico Agroindustriales por la Universidad Autónoma Chapingo. Profesor de El Colegio de Sonora en el Centro de Estudios en Gobierno y Asuntos Públicos. Línea de investigación: gestión y políticas públicas del agua potable. Publicación más reciente: Fugas de agua y dinero. Factores político institucionales que inciden sobre el desempeño de los organismos operadores de agua potable en México. 